\title{
Increasing male engagement in the prevention of vertical transmission of HIV: what works in sub-Saharan Africa?
}

\author{
Muktar Aliyu and colleagues discuss barriers, enablers, and research gaps in engaging male \\ partners in prevention of vertical HIV transmission in sub-Saharan Africa
}

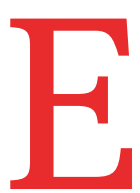

nding vertical transmission of HIV, or maternal-to-infant passage of HIV during pregnancy, labour, or postpartum, in subSaharan Africa will require innovations beyond current biomedical tools. Available evidence indicates that involvement of male partners in vertical transmission prevention programmes is such an innovation. Support from a male partner is associated with enhanced maternal HIV testing during pregnancy, increased initiation and adherence to maternal antiretroviral therapy, improved HIV communication and prevention among couples, and decreased vertical transmission, with attendant increase in HIV-free infant survival. $^{12}$

Stagnation in progress on the reduction in vertical transmission in parts of subSaharan Africa, ${ }^{2}$ coupled with greater numbers of people living with HIV and advances in antiretroviral therapy, increase the need to accelerate the scale-up of effective strategies. Despite the prioritisation of active engagement of male partners in many sub-Saharan Africa countries, explicit implementation guidelines are largely absent in national policy documents. ${ }^{3}$ Variability of definitions and strategies of male partner engagement, coupled with wide differences

\section{KEY MESSAGES}

- Interventions to increase male engagement in vertical transmission prevention need adaptation to local sociocultural contexts

- Vertical transmission prevention should include improving community level education on vertical transmission and reframing cultural norms to include men in prenatal care

- A substantial gap exists in vertical transmission knowledge, including a lack of consensus about definitions of male partner engagement and a paucity of rigorous cost effectiveness data in sociocultural contexts, complicate the translation of research into policy and practice. We synthesise what is known about successful male partner involvement interventions for prevention of vertical transmission in sub-Saharan Africa, highlight implementation challenges, and identify questions for further research.

\section{Challenges in studying male partner involvement}

Low background levels of male partner involvement in antenatal care

The first step in the vertical transmission prevention cascade is maternal HIV testing and counselling at antenatal care clinics. Many countries in sub-Saharan Africa have persistently low attendance by antenatal care among women and men. For example, in Nigeria, only $51 \%$ of pregnant women meet World Health Organization recommendations of at least four antenatal care visits. ${ }^{4}$ Data on male antenatal care attendance are often not collected or reported; measures are typically based on the number of male partners attending at least one antenatal care visit. Barriers to male attendance at and involvement in antenatal care and vertical transmission prevention services operate at multiple levels: community (for example, gender norms/ roles in reproductive health, HIV related stigma), health system (for example, female oriented services, negative provider attitudes), interpersonal (for example, couple mistrust, disclosure issues), and individual (for example, poor maternal knowledge of child health, fear of HIV related stigma)..$^{5-8}$ These factors similarly limit male involvement in subsequent steps on the vertical transmission prevention cascade.

Varied sociocultural contexts, including gender roles and power dynamics

Different sociocultural contexts and norms within and between countries highlight difficulties in generalising specific approaches to male involvement in maternal healthcare in sub-Saharan Africa. These variations include gender roles, social expectations and traditions in reproduction and childcare, cultural systems such as family structures (including polygamous unions), and the role of the extended family in reproductive decision making. ${ }^{9}$

Issues surrounding gender roles and power are especially relevant and serve as barriers to both male and female participation in maternal health services. Socioculturally entrenched expectations typically feminise participation in antenatal services and masculinise decision making. ${ }^{89}$ Hence, men often avoid participating and women may defer critical decisions exclusively to men. Fear of intimate partner violence may be part of a dysfunctional dynamic, leading women to decline HIV testing or antiretroviral therapy. Yet, accountability for maternal health service uptake and adverse outcomes is largely shouldered by women. ${ }^{9}$

Measurement challenges, including varying definitions for male partner involvement Defining and measuring male involvement is important for evaluating the effect of male involvement on services for prevention of vertical HIV transmission and comparing findings across studies. Many definitions of for male partner involvement have been used in the literature. A commonly used definition denotes men having adequate knowledge of, and participation in, maternal health related activities and acting as supportive partners in decision making for improved maternal and child outcomes. ${ }^{6}$ Possible measures of involvement include antenatal HIV testing of male partners; couples' HIV counselling and testing; and male attendance at antenatal care, deliveries, or postpartum visits. ${ }^{12610}$ A composite indicator has been developed based on an "involvement index" of several factors, including male attendance at antenatal care, HIV testing, maternal economic support, knowledge and awareness of antenatal care services, and participation in contraception decision making. ${ }^{611}$ Other 
challenges include the lack of data on the ideal "level" of male partner engagement and failure to account for the variation in male partner involvement over time. The logical follow-up question therefore arises: what level of male engagement are policy makers striving to achieve to end vertical transmission and optimise outcomes for the mother, her partner, and their child?

\section{Male partner involvement strategies as a component of bundled interventions}

Male engagement activities are increasingly being integrated into vertical transmission prevention programmes as components of bundled interventions. ${ }^{10}$ However, this makes it difficult to attribute any effect seen on outcomes to male engagement strategies. A multisite Mozambique study engaged traditional birth attendants to deliver health services to pregnant women, trained community based male counsellors, created private rooms for couples having counselling and testing, and implemented community based theatre to destigmatise male partner support. ${ }^{5}$ Although the intervention increased male partner engagement from 5\% to 34\% (defined as partner accompaniment to antenatal care services at least once), it was not possible to identify which components were most successful. ${ }^{5}$ Bundled interventions can also be inefficient, as not all participants may need the same intensity of interventions and some individuals may receive services that they do not need.

\section{Unintended effects}

Women should be the final arbiters of their preferred level of male partner engagement. Some women may fear loss of privacy or autonomy if men cross into their "space." These women may be most comfortable managing their care independently, while others benefit from partner support. Male involvement strategies should also be designed to minimise potential negative effects of increasing male participation. Such negative effects could include decreased exclusive breastfeeding or early breastfeeding cessation, intimate partner violence, or pressure to alter a woman's health service preferences. ${ }^{12}$ These effects could have unintended consequences on uptake of maternal services and overall maternal and child health. In extreme cases, denying antenatal care services to women who present without male partners (whether by protocol or by overzealous practitioners) can discourage uptake and hinder access to early initiation of maternal care. $^{91213}$

\section{Available evidence from individual studies}

Bundled interventions that integrate male partner involvement showed effectiveness in a 2017 meta-analysis that included four randomised controlled trials and 13 observational studies. ${ }^{10}$ In Nigeria, a cluster randomised controlled trial of bundled interventions (male involvement, task shifting, point-of-care CD4 testing, and integrated postpartum maternal and child health services) increased antiretroviral therapy uptake, maternal and infant retention in care, and HIV-free infant survival. ${ }^{14}$ In rural Mozambique, trained male-to-male counsellors and traditional birth attendants were associated with increased uptake of counselling, testing, and antiretroviral therapy among pregnant women..$^{5}$ In Kenya, a bundled intervention focused on demand creation (eg, community mobilisation), use of technology (eg, text reminders to male partners), and service delivery innovations (eg, invitation letters). The intervention was associated with improved linkage to HIV care, decreased time to initiation of antiretroviral therapy, and increased facility based delivery among pregnant women. ${ }^{2}$ The use of community liaison officers such as community health workers and male champions can also affect the effectiveness of bundled interventions. ${ }^{14}$ The dearth of cost effectiveness analyses, however, limits conclusions regarding the usefulness of these bundled interventions.

Psychosocial approaches to increasing male partner involvement, including peer facilitated support groups and cognitive behavioural approaches, have increased male antenatal care attendance with improved maternal outcomes. ${ }^{8} 10$ For example, the PartnerPlus intervention in South Africa comprised weekly sessions for pregnant women and their partners to improve interpersonal communication skills, medication adherence, HIV knowledge, condom use, and disclosure. ${ }^{15}$ The study found an increase in knowledge of HIV and vertical transmission prevention. ${ }^{15}$

Verbal encouragement by clinic providers may motivate pregnant women to bring male partners to antenatal care. ${ }^{116}$ One study found that verbal invitations to male partners had positive effects on rates of partner return and couple HIV counselling and testing ${ }^{7}$. In Malawi, verbal encouragement improved condom use and maternal retention in care but not maternal uptake of antiretroviral therapy. ${ }^{16}$

Provider assisted partner invitation via letter is widely used to promote male involvement. ${ }^{7817-19}$ At least two randomised controlled trials have shown an impact on male involvement, ${ }^{17} 18$ although invitation letters may not have improved uptake of maternal or infant antiretroviral therapy. ${ }^{10} 19$ Jefferys et al reported that use of invitation letters resulted in comparatively higher rates of male partner antenatal care attendance at rural versus urban facilities in Tanzania. ${ }^{20}$ Similarly, work in South Africa found letters particularly motivational if focused on fatherhood and primary healthcare, rather than HIV testing. ${ }^{21}$

Community education and sensitisation. Limited knowledge of vertical transmission risk can hinder men's participation. ${ }^{78}$ Education and sensitisation programmes engaging community leaders and men as role models can increase vertical transmission knowledge and awareness among men, combat negative attitudes, ${ }^{3}$ and improve healthcare engagement. ${ }^{5}$ The effect of such initiatives may not be limited to vertical transmission prevention. In Tanzania, a community focused lifesaving skills curriculum significantly increased male partner involvement in maternal health (defined by a composite indicator) from $39 \%$ to $81 \% .{ }^{22}$ Community education and sensitisation campaigns must focus on sustaining behaviour change; in Mozambique a community based programme resulted in long term engagement. $^{5}$

\section{Evidence from systematic reviews and meta- analyses}

High quality evidence- for example, from randomised studies-on the effect of male partner involvement on vertical transmission prevention outcomes is lacking. Study heterogeneity also makes it challenging to reliably pool findings for metaanalyses. A Cochrane review ${ }^{23}$ included only one eligible study, which provided invitation letters to pregnant women with an unexpected negative effect on uptake of a vertical transmission prevention service. Takah and colleagues included 17 articles, also finding that invitation letters were ineffective in improving male partner involvement. ${ }^{10}$ The most effective strategies were psychosocial approaches delivered by trained personnel and complex community interventions (table 1). ${ }^{10}$ A systematic review assessing barriers and facilitators to male engagement showed that one major barrier is the societal perception that maternal health related services are "women's activities." ${ }^{8}$ Facilitators were related to health system or community interventions, including sensitisa- 


\begin{tabular}{|c|c|c|c|}
\hline $\begin{array}{l}\text { Socioecological } \\
\text { level }\end{array}$ & Barriers & Enablers & Ineffective in some studies \\
\hline \multirow{4}{*}{$\begin{array}{l}\text { Individual } \\
\text { (male partner) }\end{array}$} & ${ }^{\dagger}$ Reluctance to learn HIV status ${ }^{8}$ & $\begin{array}{l}\text { Invitation letters for couple testing and counselling (delivered } \\
\text { by community leader or female partner) }{ }^{8} \text {, or to promote } \\
\text { fatherhood and primary healthcare }\end{array}$ & $\begin{array}{l}\text { Invitation letter for couple testing } \\
\text { and counselling delivered by } \\
\text { female partner }^{1023}\end{array}$ \\
\hline & $\begin{array}{l}{ }^{\dagger} \text { Limited HIV and vertical transmission } \\
\text { knowledge }^{8}\end{array}$ & Prior HIV testing $^{8}$ & \multirow[t]{3}{*}{ Verbal encouragement/invitation ${ }^{10}$} \\
\hline & ${ }^{\dagger}$ Lack of time for involvement ${ }^{8}$ & Prior knowledge of $\mathrm{HIV}^{8}$ & \\
\hline & Fear of stigma9 & & \\
\hline \multirow{5}{*}{$\begin{array}{l}\text { Interpersonal (with } \\
\text { female partner(s)) }\end{array}$} & $\begin{array}{l}\text { Fear of stigma/abandonment/ } \\
\text { domestic violence }\end{array}$ & Monogamous marriage and cohabitation partnerships ${ }^{24}$ & $\begin{array}{l}\text { Male partner invitation letter for } \\
\text { couple testing and counselling } \\
\text { delivered by female partner }{ }^{1023}\end{array}$ \\
\hline & Poor communication among couples ${ }^{8}$ & Couples discussing vertical transmission prevention ${ }^{8}$ & \multirow{4}{*}{$\begin{array}{l}\text { Verbal encouragement/invitation } \\
\text { delivered by female partner }{ }^{10}\end{array}$} \\
\hline & \multirow[t]{3}{*}{ Mistrust/fidelity issues ${ }^{8}$} & Seroconcordance for $\mathrm{HIV}^{8}$ & \\
\hline & & $\begin{array}{l}\text { Positive attitude on HIV status disclosure among female } \\
\text { partners }\end{array}$ & \\
\hline & & Financial dependence of women on male partners ${ }^{9}$ & \\
\hline \multirow{4}{*}{$\begin{array}{l}\text { Health facility/ } \\
\text { health system }\end{array}$} & Discourteous healthcare workers $^{824}$ & $\begin{array}{l}\text { Vertical transmission prevention service delivery to men } \\
\text { outside antenatal care clinics/hours }{ }^{8}\end{array}$ & \\
\hline & $\begin{array}{l}\text { Male unfriendliness of maternal healthcare } \\
\text { clinics }^{824}\end{array}$ & Couple testing and counselling as standard of care ${ }^{8}$ & \\
\hline & Long clinic waiting times ${ }^{8}$ & Healthcare worker facilitation of disclosure process ${ }^{8}$ & \\
\hline & Distrust in confidentiality of health system & ${ }^{\dagger}$ Psychosocial interventions delivered by trained staff ${ }^{10}$ & \\
\hline \multirow{3}{*}{ Community/society } & $\begin{array}{l}{ }^{\dagger} \text { Gendered norms for antenatal care and vertical } \\
\text { transmission prevention service interaction/ } \\
\text { utilisation }{ }^{824}\end{array}$ & Community education and sensitisation ${ }^{8}$ & \\
\hline & $\begin{array}{l}\text { Lack of community awareness of the importance } \\
\text { of male involvement }{ }^{8}\end{array}$ & \multirow[t]{2}{*}{$\begin{array}{l}{ }^{\dagger} \text { Complex community interventions (combining couple, } \\
\text { healthcare, and community targeted strategies) }{ }^{10}\end{array}$} & \\
\hline & $\begin{array}{l}\text { Vertical transmission prevention teachings in } \\
\text { conflict with sociocultural norms }^{8}\end{array}$ & & \\
\hline Government/policy & $\begin{array}{l}\text { Policies that fail to prioritise, accommodate and/ } \\
\text { or detail male involvement }{ }^{2}\end{array}$ & & \\
\hline
\end{tabular}

${ }^{*}$ According to findings from systematic reviews and meta-analyses ${ }^{810} 2324$

tMost influential/impactful findings overall

tion education, provider encouragement, invitation letters, couples' discussions, and male partner counselling and testing outside the antenatal care setting. Predictors of male involvement included monogamous marriage or cohabitation, HIV seroconcordance, and female partners' financial dependence on men (table 1). ${ }^{8}$ A systematic review of 28 studies from sub-Saharan Africa found that whereas few papers looked at the perceived role of men in vertical transmission services, most included considerations of barriers and enablers to male participation. ${ }^{24}$

\section{What changes do national HIV programmes need to institute?}

While acknowledging the need to adapt to sociocultural context, evidence suggests that interventions should target three key factors: community education on vertical transmission, particularly tackling norms regarding male participation in maternal services; community based counselling of male partners to encourage and support maternal antenatal care attendance; and availability of trained health providers, private space, and couples based counselling and testing services within health facilities.
Additionally, male partner engagement should not be tied to maternal HIV status; women should not be penalised if their partners do not participate; and neither should women be solely responsible for their partner's participation. Governments should support male engagement initiatives by enabling structural and policy changes, including prioritising funding and implementation of such initiatives. Public policies should also promote the engagement of community leaders as change agents to tackle socioeco-

nomic and cultural norms that impede vertical transmission prevention.

\section{Further research}

Further research should focus on reducing harmful gender norms and practices and the stigma associated with men attending maternal health services (box 1). In addition, several approaches to increase male partner attendance in antenatal care have been tested, but there is little consensus about how strategies should be tai-

Box 1: Improving male partner involvement in vertical transmission prevention: key questions for further research

- Definition of male engagement/involvement and target level of involvement ${ }^{311}$

- Disentangling individual component effectiveness within bundled interventions $s^{51014}$

- Comparative cost effectiveness studies of various interventions ${ }^{3}$

- Impact of male partner involvement interventions in rural versus urban settings ${ }^{20}$

- Culturally sensitive interventions to influence gender norms harmful to male involvement ${ }^{5}$

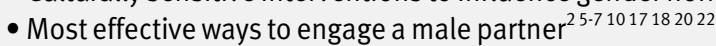

- Reframing maternal health and vertical transmission prevention to incorporate men's roles

- Engaging men to define their role in vertical transmission prevention and craft feasible,

sustainable interventions

- Allowing women to define the role(s) they want their partner to have in vertical transmission prevention ${ }^{91321}$

- Improving healthcare provider attitudes to male involvement ${ }^{824}$ 
lored to specific conditions (rural versus urban; married versus cohabiting couples; strength of relationship; and so on). We lack data about what constitutes male partner involvement and what level of engagement is sufficient to maximise women's uptake of vertical transmission prevention services. ${ }^{11}$ Simple, male targeted interventions such as peer psychosocial initiatives show promise as standalone strategies, but like others, they are effective only if developed in partnership with community stakeholders, including women. Lastly, cost effectiveness analyses of such interventions are essential to justify the efficient use of increasingly limited PEFPAR, Global Fund, or national health system funds.

Contributors and sources: MA is associate professor and associate director for research with the Vanderbilt Institute for Global Health; NS is assistant professor of paediatrics with the Institute of Human Virology, University of Maryland School of Medicine; SS is assistant professor in the AIDS Care Program of the Yale University School of Medicine; AG is chief specialist scientist, TR is a scientist with the South Africa Medical Research Council; CA is assistant professor in the Vanderbilt Institute of Global Health; SV is dean of the Yale School of Public Health. MA, NS, CA and AG conceptualised the study. SS, TR, and SV contributed to study methodology and data interpretation; all authors contributed to methodology, validation, writing original draft, review, and editing. MA is the guarantor.

Competing interests: All authors have read and understood the BMJ policy on declaration of interests and declare no competing interests.

Provenance and peer review: Commissioned; externally peer reviewed.

This article is part of a series proposed by the South African Medical Research Council and commissioned by The BMJ. The BMJ retained full editorial control over external peer review, editing, and publication. Open access fees are funded by the South African Medical Research Council.

Muktar H Aliyu, associate professor ${ }^{1}$

Nadia A Sam Agudu, associate professor ${ }^{2,3}$

Sheela Shenoi, assistant professor ${ }^{4}$

Ameena E Goga, researcher ${ }^{5,6}$

Trisha Ramraj, researcher ${ }^{5}$

Sten $\mathrm{H}$ Vermund, professor ${ }^{4}$

Carolyn M Audet, assistant professor

${ }^{1}$ Vanderbilt Institute for Global Health, Vanderbilt University Medical Center, Nashville, USA

${ }^{2}$ Institute of Human Virology, University of Maryland School of Medicine, Baltimore, USA

${ }^{3}$ Institute of Human Virology, Abuja, Nigeria

${ }^{4}$ School of Medicine, Yale University, New Haven, USA

${ }^{5}$ South African Medical Research Council, Pretoria, South Africa

${ }^{6}$ Department of Paediatrics, University of Pretoria, South Africa

Correspondence to: M H Aliyu

muktar.aliyu@vumc.org

\section{ळO OPEN ACCESS}

This is an Open Access article distributed in accordance with the Creative Commons Attribution Non Commercial (CC BY-NC 4.0) license, which permits others to distribute, remix, adapt, build upon this work non-commercially, and license their derivative works on different terms, provided the original work is properly cited and the use is non-commercial. See: http://creativecommons.org/ licenses/by-nc/4.0/.

\section{Check for updates}

1 Aluisio A, Richardson BA, Bosire R, John-Stewart G, Mbori-Ngacha D, Farquhar C. Male antenatal attendance and HIV testing are associated with decreased infant HIV infection and increased HIV-free survival. J Acquir Immune Defic Syndr 2011;56:7682. doi:10.1097/QAl.0b013e3181fdb4c4

2 Akama E, Mburu M, Mutegi E, et al. Impact of a rapid results initiative approach on improving male partner involvement in prevention of mother to child transmission of HIV in Western Kenya. AIDS Behav 2018;22:2956-65. doi:10.1007/s10461 018-2140-3

3 van den Berg W, Brittain K, Mercer G, et al. Improving men's participation in preventing mother-to-child transmission of HIV as a maternal, neonatal, and child health priority in South Africa[Erratum in: PLoS Med 2015;12:e1001836]. PLoS Med 2015;12:e1001811. doi:10.1371/journal. pmed.1001811

4 World Health Organisation. Global Health Observatory data repository. WHO, 2016. http://apps.who.int/gho/data/node.main. REPWOMEN39?lang=en

5 Audet CM, Blevins M, Chire YM, et al. Engagement of men in antenatal care services: increased HIV testing and treatment uptake in a community participatory action program in Mozambique. AIDS Behav 2016;20:2090-100. doi:10.1007/s10461 016-1341-x

6 Byamugisha R, Åstrøm AN, Ndeezi G, Karamagi CA, Tylleskär T, Tumwine JK. Male partner antenatal attendance and HIV testing in eastern Uganda: a randomized facility-based intervention trial. J Int AIDS Soc 2011;14:43. doi:10.1186/1758-2652-14-43

7 Theuring S, Jefferys LF, Nchimbi P, Mbezi P, Sewangi J. Increasing partner Attendance in antenatal care and HIV testing services: comparable outcomes using written versus verbal invitations in an urban facility-based controlled intervention trial in Mbeya, Tanzania. PLoS One 2016;11:e0152734 doi:10.1371/journal.pone.0152734

8 Morfaw F, Mbuagbaw L, Thabane L, et al. Male involvement in prevention programs of mother to child transmission of HIV: a systematic review to identify barriers and facilitators. Syst Rev 2013;2:5 doi:10.1186/2046-4053-2-5

9 Lodenstein E, Pedersen K, Botha K, Broerse JEW, Dieleman M. Gendered norms of responsibility: reflections on accountability politics in maternal health care in Malawi. Int J Equity Health 2018;17:131. doi:10.1186/s12939-0180848-3

10 Takah NF, Kennedy ITR, Johnman C. The impact of approaches in improving male partner involvement in the prevention of mother-to-child transmission of HIV on the uptake of maternal antiretroviral therapy among HIV-seropositive pregnant women in sub-Saharan Africa: a systematic review and metaanalysis. BMJ Open 2017;7:e018207. doi:10.1136/ bmjopen-2017-018207

11 Oyugi E, Gura Z, Boru W, et al. Male partner involvement in efforts to eliminate mother-to-child transmission of HIV in Kisumu County, Western Kenya, 2015. Pan Afr Med J 2017;28(suppl 1):6. doi:10.11604/pamj.supp.2017.28.1.9283
12 Tokhi M, Comrie-Thomson L, Davis J, Portela A, Chersich M, Luchters S. Involving men to improve maternal and newborn health: A systematic review of the effectiveness of interventions. PLoS One 2018;13:e0191620. doi:10.1371/journal. pone.0191620

13 Peneza AK, Maluka SO. 'Unless you come with your partner you will be sent back home': strategies used to promote male involvement in antenatal care in Southern Tanzania. Glob Health Action 2018;11:1449724. doi:10.1080/16549716 .2018 .1449724

14 Aliyu MH, Blevins M, Audet CM, et al. Integrated prevention of mother-to-child HIV transmission services, antiretroviral therapy initiation, and maternal and infant retention in care in rural northcentral Nigeria: a cluster-randomised controlled trial. Lancet HIV 2016;3:e202-11. doi:10.1016/S23523018(16)00018-7

15 Weiss SM, Peltzer K, Villar-Loubet O, Shikwane ME, Cook $\mathrm{R}$, Jones DL. Improving PMTCT uptake in rural South Africa. J Int Assoc Provid AIDS Care 2014;13:269-76. doi:10.1177/2325957413488203

16 Kalembo FW, Zgambo M, Mulaga AN, Yukai D, Ahmed $\mathrm{NI}$. Association between male partner involvement and the uptake of prevention of mother-to-child transmission of HIV (PMTCT) interventions in Mwanza district, Malawi: a retrospective cohort study. PLoS One 2013;8:e66517. doi:10.1371/journal. pone.0066517

17 Mohlala BK, Boily MC, Gregson S. The forgotten half of the equation: randomized controlled trial of a male invitation to attend couple voluntary counselling and testing. AIDS 2011;25:1535-41. doi:10.1097/ QAD.0b013e328348fb85

18 Nyondo AL, Choko AT, Chimwaza AF, Muula AS. Invitation cards during pregnancy enhance male partner involvement in prevention of mother to child transmission (PMTCT) of human immunodeficiency virus (HIV) in Blantyre, Malawi: a randomized controlled open label trial. PLOS One 2015;10:e0119273. doi:10.1371/journal. pone.0119273

19 Takah NF, Atem JA, Aminde LN, Malisheni M, Murewenhema G. Male partner involvement in increasing the uptake of infant antiretroviral prophylaxis/treatment in sub Saharan Africa: A systematic review and metaanalysis. BMC Public Health 2018;18:249. doi:10.1186 s12889-018-5171-9

20 Jefferys LF, Nchimbi P, Mbezi P, Sewangi J, Theuring S. Official invitation letters to promote male partner attendance and couple voluntary HIV counselling and testing in antenatal care: an implementation study in Mbeya Region, Tanzania. Reprod Health 2015;12:95. doi:10.1186/s12978-015-0084-x

21 Yende N, Van Rie A, West NS, Bassett J, Schwartz SR. Acceptability and preferences among men and women for male involvement in antenatal care. J Pregnancy 2017;2017:4758017. doi:10.1155/2017/4758017

22 August F, Pembe AB, Mpembeni R, Axemo P, Darj E. Community health workers can improve male involvement in maternal health: evidence from rural Tanzania. Glob Health Action 2016;9:30064. doi:10.3402/gha.v9.30064

23 Brusamento S, Ghanotakis E, Tudor Car L, vanVelthoven MH, Majeed A, Car J. Male involvement for increasing the effectiveness of prevention of motherto-child HIV transmission (PMTCT) programmes. Cochrane Database Syst Rev 2012;10:CD009468.

24 Manjate Cuco RM, Munguambe K, Bique Osman N, Degomme O, Temmerman M, Sidat MM. Male partners' involvement in prevention of motherto-child HIV transmission in sub-Saharan Africa: a systematic review. SAHARA / 2015;12:87-105. doi:1 $0.1080 / 17290376.2015 .1123643$

Cite this as: $B M / 2019 ; 365: 11965$

http://dx.doi.org/10.1136/bmj.l1965 